\title{
Release of heat shock proteins from human neuroblastoma cells exposed to acrylamide
}

\author{
Tomoyuki Sumizawa and Hideki Igisu \\ Department of Environmental Toxicology, Institute of Industrial Ecological Sciences, \\ University of Occupational and Environmental Health, \\ 1-1 Iseigaoka, Yahatanishi, Kitakyushu 807-8555, Japan
}

(Received October 26, 2007; Accepted November 8, 2007)

\begin{abstract}
When human neuroblastoma cells (SH-SY5Y) were exposed to 0.5 - $5 \mathrm{mM}$ acrylamide for $18 \mathrm{hr}$, the levels of heat shock proteins (HSPs) of 90, 70 and $27 \mathrm{kDa}$ (Hsp90, Hsp70, and Hsp27, respectively) were elevated in the incubation media depending on the dose of acrylamide whereas only the Hsp70 level increased within cells. U0126, a specific inhibitor of extracellular signal-regulated protein kinase kinase and a potent suppressor of the cytotoxicity of acrylamide, suppressed the increase in the levels of all HSPs in the incubation media but not their expression within cells. Total protein concentrations in the incubation media increased depending on the dose of acrylamide, and this increase was associated with the increasing number of bands detected by silver staining after SDS-polyacrylamide gel electrophoresis. One of the clearest bands was identified as Hsp90 by peptide mass fingerprinting. Thus, acrylamide causes release of proteins, including that of HSPs, from SH-SY5Y cells. HSP in extracellular fluid may be a good indicator of cytotoxicity of acrylamide.
\end{abstract}

Key words: Acrylamide; Neurotoxicity; SH-SY5Y cells; Heat shock protein; ERK; Extracellular fluid

\section{INTRODUCTION}

Acrylamide has long been known to be a potent neurotoxin in humans and animals (Igisu et al., 1975), although the mechanisms of its action have not been clarified. One of the characteristic morphological alterations caused by acrylamide is distal axonal swelling associated with the accumulation of neurofilaments (Gold and Schaumburg, 2000). Acrylamide also causes aggregation of intermediate filaments in cultured cells (Blain et al., 2006).

Heat shock proteins (HSPs) are molecular chaperones for proteins; they are present in all cells, and serve to prevent protein misfolding and aggregation (Hartl and HayerHartl, 2002). Judging from the morphological changes induced by acrylamide, it possibly has an effect on levels of HSPs. Indeed, Gold et al. (2004) reported low immunostaining of $70 \mathrm{kDa} \mathrm{HSP}$ (Hsp70) in the brain of rats intoxicated with acrylamide. Saito et al. (2005) reported that a high concentration of acrylamide $(10 \mathrm{mM})$ enhanced the expression and release of HSPs in nonneuronal cells (HeLa cells and normal rat kidney cells). In our previous studies, we found that acrylamide causes apoptosis in human neuronal cells (SH-SY5Y) and that signal transduction mediated by extracellular signal-regulated protein kinase (ERK) plays an important role (Okuno et al., 2006; Sumizawa and Igisu, 2007), while HSPs have been shown to influence signal transduction leading to cell death (Xanthoudakis and Nicholson, 2000). We therefore examined HSPs inside and outside SH-SY5Y cells exposed to acrylamide.

\section{MATERIALS AND METHODS}

\section{Materials}

Bio-Safe CBB G-250 Stain and Aurum Serum Protein Mini Kit were purchased from Bio-Rad (Hercules, CA, USA). Silver Stain Kit was obtained from Wako Pure Chemical Industries (Osaka, Japan). Polyclonal antibodies against Hsp90, Hsp70 and Hsp27 from Stressgen (Victoria, BC, Canada). Polyclonal anti-actin and HRPconjugated donkey anti-goat IgG from Santa Cruz Biotechnology (Santa Cruz, CA, USA). Immobilon-P Transfer Membrane and Immobilon Western Detection Reagents (chemiluminescent HRP substrate) from Milli-

Correspondence: Hideki Igisu (E-mail: igisu@med.uoeh-u.ac.jp) 
pore Corporation (Billerica, MA, USA). Aprotinin and Igepal CA-630 from Sigma (St. Louis, MO, USA). SHSY5Y human neuroblastoma cells from American Type Culture Collection. The sources of all other chemicals and kits were the same as described previously (Okuno et al., 2006; Sumizawa and Igisu, 2007).

\section{Cell culture and treatments}

SH-SY5Y cells were grown as described previously (Sumizawa and Igisu, 2007), and the exponentially growing cells were plated at 1.3-2.4 × $10^{6}$ cells/well in 6-well culture plates and cultured for 2 days prior to the experiments. The medium was changed to $1 \mathrm{ml}$ of serum-free DMEM/F12 containing acrylamide or without it and cells were incubated for $18 \mathrm{hr}$. The serum-free medium was used to avoid possible binding of acrylamide to the serum proteins. Incubation in serum-free DMEM/F12 for $24 \mathrm{hr}$ did not lower the viability of SH-SY5Y cells. To examine the effect of U0126, cells were pretreated for $1 \mathrm{hr}$ with U0126 in serum-free medium and then exposed to acrylamide for $18 \mathrm{hr}$. Heat shock treatment was performed as described by Quigney et al. (2003), i.e., cells were placed at $41.5^{\circ} \mathrm{C}$ in a humidified $5 \% \mathrm{CO}_{2}$ atmosphere for $1 \mathrm{hr}$ and then allowed to recover at $37^{\circ} \mathrm{C}$ for $6 \mathrm{hr}$ before they were exposed to acrylamide. The cytotoxicity detection (lactate dehydrogenase (LDH) assay) and cell viability tests (water soluble tetrazolium (WST)-8 assay) were carried out as described previously (Sumizawa and Igisu, 2007).

\section{Immunoblotting}

After removing the medium, culture plates were rinsed with ice-cold phosphate buffered saline (PBS) containing $1 \%$ aprotinin, cells were scraped with $100 \mu 1$ of RIPA buffer (PBS containing 1\% Igepal CA-630, 0.5\% sodium deoxycholate, $0.1 \%$ sodium dodecyl sulfate (SDS), 0.1 $\mathrm{mg} / \mathrm{ml}$ phenylmethylsulphonyl fluoride, $30 \mathrm{ml} / \mathrm{ml}$ of aprotinin and $1 \mathrm{mM}$ sodium orthovanadate). The cell lysate was passed through a 21-gauge needle 10 times. After left on ice for $30 \mathrm{~min}$, the cell lysate was centrifuged at 15,000 $\times \mathrm{g}$ for $20 \mathrm{~min}$ at $4^{\circ} \mathrm{C}$. The supernatant was used as the total cell lysate. One-hundredth volume of the culture medium or 15 or $30 \mu \mathrm{g}$ of protein from the total cell lysate was loaded onto $10 \%$ SDS-polyacrylamide gels. The proteins were transferred onto an Immobilon-P membrane, and the membrane was treated with polyclonal primary antibodies (against Hsp90, Hsp70, Hsp27, or actin), horse radish peroxidase (HRP)-conjugated secondary antibodies, followed by chemiluminescent HRP substrate. The intensities of the bands were quantified by a CoolSaver AE-6955 using CS Analyzer Ver2.0 (ATTO Corporation, Tokyo, Japan).

\section{Protein analysis}

The concentrations of the proteins were measured by Protein Assay based on the Bradford method. Ten $\mu$ of the culture medium was resolved on $10 \%$ SDS-polyacrylamide gel electrophoresis (PAGE), and proteins were stained using Silver Stain Kit (Wako) or Coomassie Brilliant Blue (CBB).

For peptide mass fingerprinting, culture media corresponding to $40 \mu \mathrm{g}$ of proteins were half-saturated with ammonium sulfate and left overnight at $4^{\circ} \mathrm{C}$. After centrifugation at $15,000 \times \mathrm{g}$ for $20 \mathrm{~min}$ at $4^{\circ} \mathrm{C}$, the pellet was resuspended in $80 \mu \mathrm{l}$ of PBS. After electrophoresis on a $10 \%$ SDS-polyacrylamide gel, the proteins were stained with CBB. Clear bands of approximately $90 \mathrm{kDa}$ were excised from the gel and placed in distilled water $(1 \mathrm{ml})$. Peptide mass fingerprinting was carried out at Hitachi High-Tech Science Systems Corporation (Hitachinaka, Japan) using oMALDI-Qq-TOF MS/MS QSTAR Pulsar i (Applied Biosystems), MASCOT (Matrix Science) and NCBInr (Taxonomy: human).

\section{RESULTS AND DISCUSSION}

Among the HSPs we examined, only the level of Hsp70 was elevated within the cells exposed to acrylamide (Fig. 1a). This elevation in the Hsp70 level was not suppressed by U0126 (Fig. 2a), a specific inhibitor of extracellular signal-regulated protein kinase kinase. In our previous studies, U0126 suppressed all indices of acrylamide cytotoxicity, including lowered trypan blue exclusion and LDH leakage, increased p53 phosphorylation, and activation of caspase 3 associated with increase in cell population in the subG1 phase (Okuno et al., 2006; Sumizawa and Igisu, 2007). This indicates that the elevation of the intracellular Hsp70 level was not related to the toxicity of acrylamide. In addition, while heat shock caused a nearly 3-fold increase in the level of Hsp70 within cells (but no increase in the levels of Hsp90 or Hsp27), the cells subjected to heat shock did not differ in response (evaluated by WST-8 and LDH assay) to acrylamide (1 - $5 \mathrm{mM}$ ) from the untreated ones (data not shown).

In contrast, the levels of Hsp90, Hsp70 and Hsp27 in the incubation media increased depending on the dose of acrylamide (Fig. 1b). Moreover, $5 \mu \mathrm{M}$ of U0126 suppressed the levels of HSP by more than $75 \%$ (Fig. 2b). Hence, extracellular HSPs appear to be closely related to the cytotoxicity of acrylamide.

Conventionally, HSPs have been regarded as an important part of the defense mechanisms of the cell because they are often expressed in response to various noxious stimuli such as oxygen deprivation, radiation and chemi- 
Acrylamide and heat shock proteins.

cals (Hartl and Hayer-Hartl, 2002). Recent studies have revealed extracellular functions of HSPs. For instance, Hsp90- $\alpha$ when expressed extracellularly activates proteinase and increases the invasiveness of tumor cells (Eustace et al., 2004). Exogenous Hsp70 binds with high affinity to the plasma membrane and activates NF- $\mathrm{KB}$ (Asea et al., 2000). Hsp70 is released from cells involving lysosomal endosomes, independent of de novo synthesis or cell death

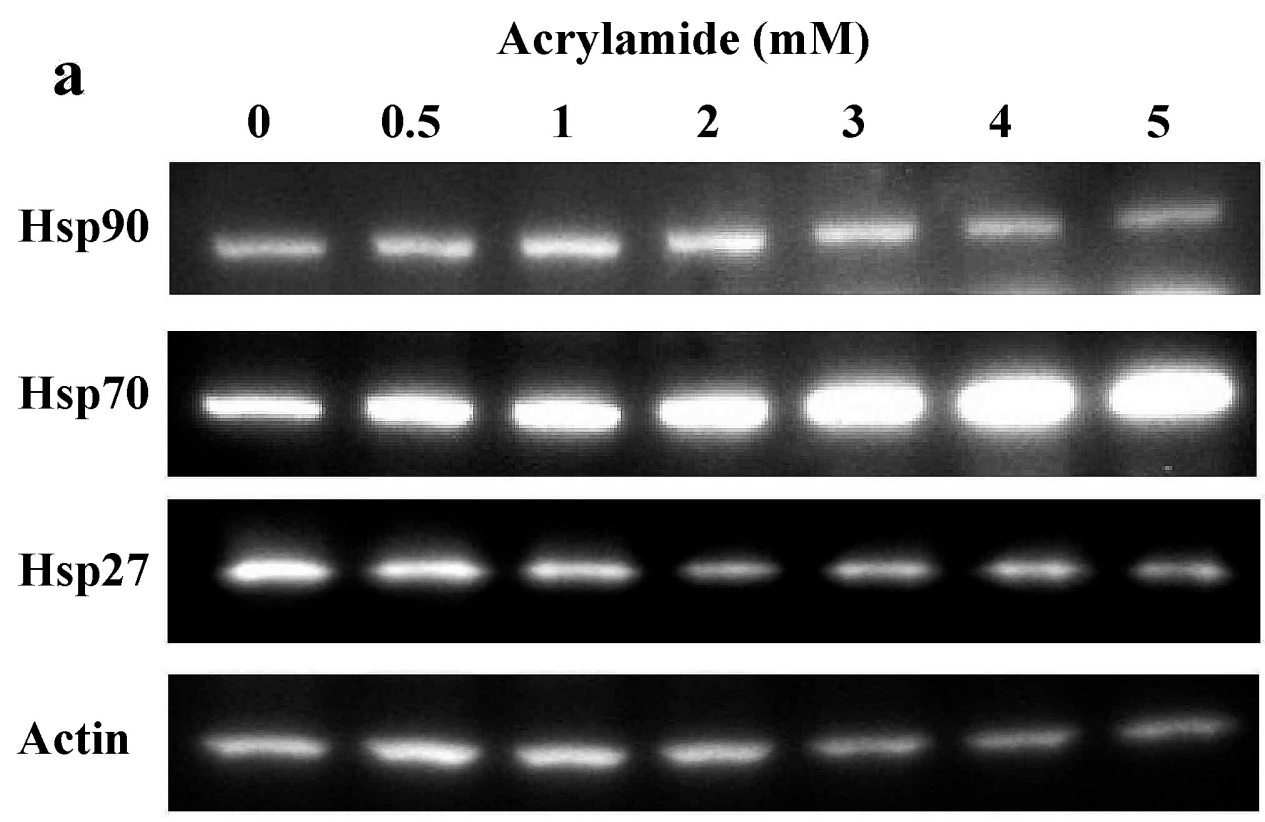

b

Hsp90

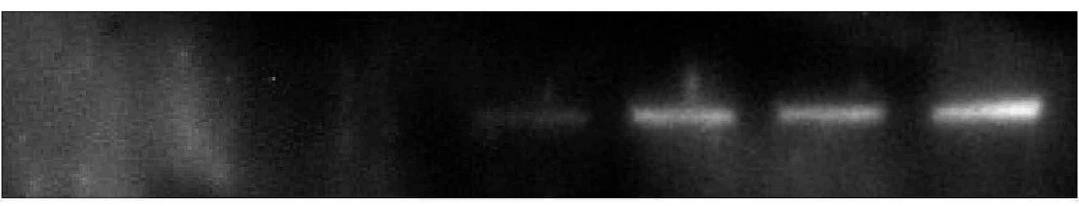

Hsp70

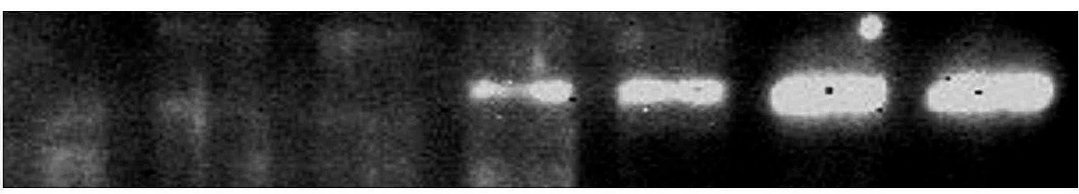

Hsp27

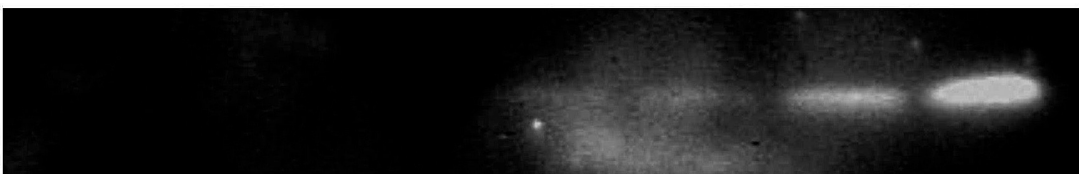

Fig. 1. Effects of acrylamide on intracellular (a) and extracellular (b) levels of heat shock proteins. SH-SY5Y cells were incubated with or without acrylamide for $18 \mathrm{hr}$. Representative immunoblots from 6 independent experiments are shown. In a densitometric analysis, the intracellular Hsp70 level was elevated significantly by 4 and $5 \mathrm{mM}$ acrylamide $(\mathrm{p}<0.001$; ANOVA followed by the Bonferroni test) but no elevation in the levels of Hsp90 and Hsp27 was observed. 
(Mambula and Calderwood, 2006). Thus HSPs can be secreted from cells via an active secretion pathway and can affect other cells. The results of the present experiment do not clearify whether the extracellular release of HSPs is caused by active processes or simply due to the damage to the cell membrane.

Apparently, when a high dose of acrylamide was administered, the increase in the extracellular protein level was not limited to that of HSPs because the concentrations $(\mu \mathrm{g} / \mathrm{ml}$, mean $\pm \mathrm{SD}$, and $\mathrm{n}=3$ ) of the total proteins were $49.2 \pm 4.6$ (when not exposed to acrylamide), $68.8 \pm 11.5$ (when exposed to $1 \mathrm{mM}$ of acrylamide), $79.1 \pm 15.6$ (2 $\mathrm{mM}$ acrylamide), $103.3 \pm 20$ (3 $\mathrm{mM}$ acrylamide $), 115.6 \pm$ 17.5 (4 mM acrylamide) and $121.7 \pm 17.5$ (5 mM acrylamide). Furthermore, numerous bands were observed with silver staining after the SDS-PAGE of the proteins in the incubation media (Fig. 3). Peptide mass fingerprinting revealed that the $90 \mathrm{kDa}$ band obtained following SDS-

$\begin{array}{llllcr}\text { Acrylamide }(\mathrm{mM}) & \mathbf{0} & \mathbf{3} & \mathbf{3} & \mathbf{3} & \mathbf{3} \\ \mathrm{U} 0126(\mu \mathrm{M}) & \mathbf{0} & \mathbf{0} & \mathbf{5} & \mathbf{1 0} & \mathbf{2 0}\end{array}$

a

$$
\text { Hsp90 }
$$

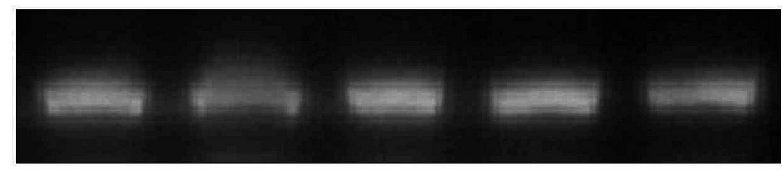

Hsp70

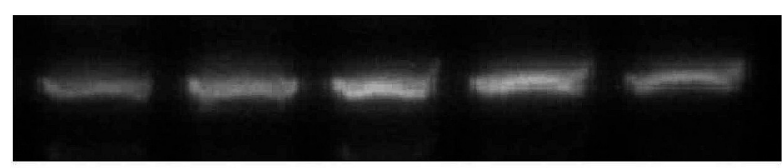

Hsp27

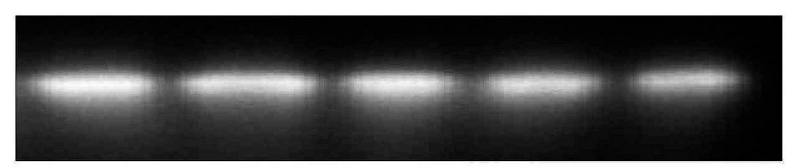

Actin

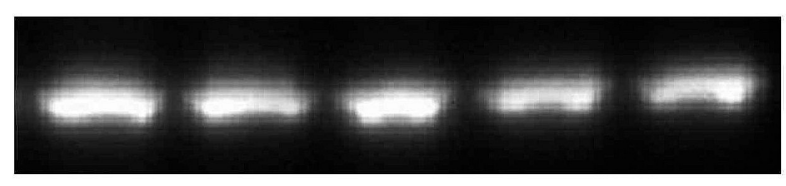

b

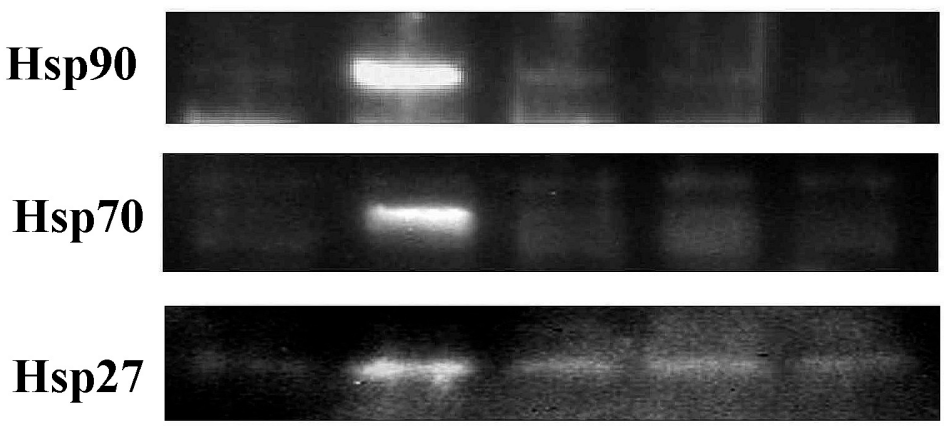

Fig. 2. Effects of extracellular signal-regulated protein kinase kinase inhibitor (U0126) on intracellular (a) and extracellular (b) levels of heat shock proteins. After SH-SY5Y cells were treated with $\mathrm{U} 0126$ for $1 \mathrm{hr}$, acrylamide (final concentration of $3 \mathrm{mM}$ ) was added and incubated further for $18 \mathrm{hr}$. Representative immunoblots from 3 independent experiments are shown. 


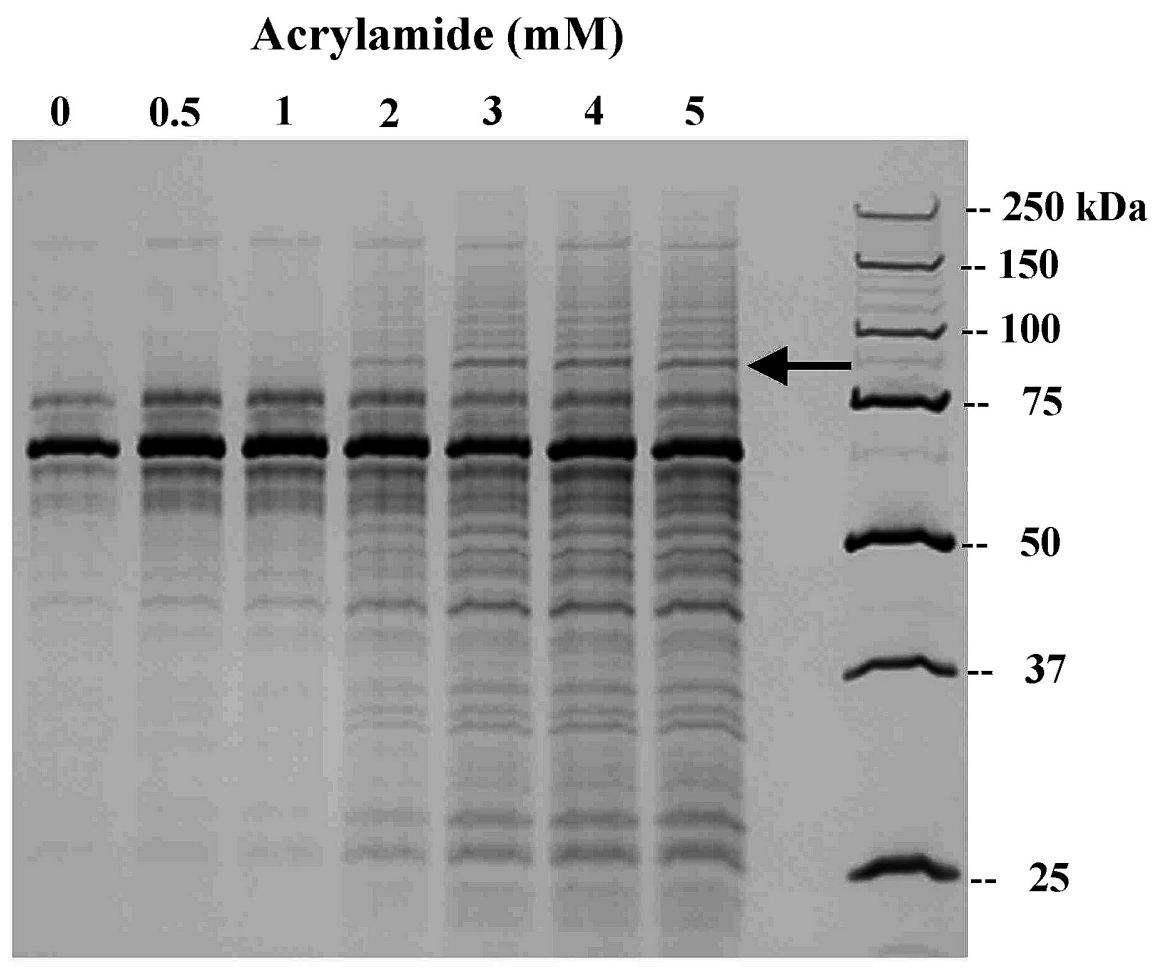

Fig. 3. Proteins in incubation media detected by silver staining following SDS-polyacrylamide gel electrophoresis. After SH-SY5Y cells were incubated with or without acrylamide for $18 \mathrm{hr}, 10 \mu \mathrm{l}$ of the incubation media was loaded. For peptide mass fingerprinting, the bands (after staining with Coomassie Brilliant Blue) indicated by the arrow were excised, and found to contain both Hsp90- $\alpha$ and Hsp90- $\beta$.

PAGE contained both Hsp90- $\alpha$ and Hsp90- $\beta$ (Homo sapiens) (This was also confirmed by immunoblotting). Thus, although the involvement of active secretion of HSPs cannot be ruled out, it appears that acrylamide impairs plasma membrane, at least at high doses, resulting in nonspecific leakage of proteins.

Although the pathogenetic significance of the changes in the levels of HSPs inside and outside SH-SY5Y cells is not yet clear, in view of the fact that HSPs are predominantly an intracellular component, extracellular levels of HSP may be a sensitive indicator of acrylamide toxicity. HSPs appear to be especially useful because their determination does not depend on enzymatic activities that may be inhibited by chemicals. Furthermore, the measurement is unlikely to be affected by the reducing substances such as glutathione whereas many methods to evaluate cytotoxicity including 3-(4,5-dimethylthiazol-2-yl)-2,5-diphenyltetrazolium bromide (MTT), WST- 8 and LDH assay are dependent on the changes of reduced form of nicotinamide adenine dinucleotide.

\section{ACKNOWLEDGMENTS}

This work was supported in part by a Grant-in Aid for Scientific Research from the Ministry of Education, Culture, Sports, Science and Technology, Japan, and by a UOEH Grant for Advanced Research.

\section{REFERENCES}

Asea, A., Kraeft, S.K., Kurt-Jones, E.A., Stevenson, M.A., Chen, L.B., Finberg, R.W., Koo, G.C. and Calderwood, S.K. (2000): HSP70 stimulates cytokine production through a CD14-dependant pathway, demonstrating its dual role as a chaperone and cytokine. Nat. Med., 6, 435-442.

Blain, E.J., Gilbert, S.J., Hayes, A.J. and Duance, V.C. (2006): Disassembly of the vimentin cytoskeleton disrupts articular cartilage chondrocyte homeostasis. Matrix. Biol., 25, 398-408.

Eustace, B.K., Sakurai, T., Stewart, J.K., Yimlamai, D., Unger, C., Zehetmeier, C., Lain, B., Torella, C., Henning, S.W., Beste, G., Scroggins, B.T., Neckers, L., Ilag, L.L. and Jay, D.G. (2004): Functional proteomic screens reveal an essential extracellular role for hsp90 alpha in cancer cell invasiveness. Nat. Cell Biol., 6, 507-514. 
T. Sumizawa et al.

Gold, B.G. and Schaumburg, H.H. (2000): Acrylamide. In Experimental and Clinical Neurotoxicology, 2nd ed. (Spencer, P.S. and Schaumburg, H.H., eds.), pp.124-132, Oxford University Press, New York.

Gold, B.G., Voda, J., Yu, X. and Gordon, H. (2004): The immunosuppressant FK506 elicits a neuronal heat shock response and protects against acrylamide neuropathy. Exp. Neurol., 187, 160-170.

Hartl, F.U. and Hayer-Hartl, M. (2002): Molecular chaperones in the cytosol: from nascent chain to folded protein. Science, 295, 18521858.

Igisu, H., Goto, I., Kawamura, Y., Kato, M., Izumi, K. and Kuroiwa, Y. (1975): Acrylamide encephaloneuropathy due to well water pollution. J. Neurol. Neurosurg. Psychiatry, 38, 581-584.

Mambula, S.S. and Calderwood, S.K. (2006): Heat shock protein 70 is secreted from tumor cells by a nonclassical pathway involving lysoso- mal endosomes. J. Immunol., 177, 7849-7857.

Okuno, T., Matsuoka, M., Sumizawa, T. and Igisu, H. (2006): Involvement of the extracellular signal-regulated protein kinase pathway in phosphorylation of p53 protein and exerting cytotoxicity in human neuroblastoma cells (SH-SY5Y) exposed to acrylamide. Arch. Toxicol., 80, 146-153.

Quigney, D.J., Gorman, A.M. and Samali, A. (2003): Heat shock protects PC12 cells against MPP+ toxicity. Brain Res., 993, 133-139.

Saito, K., Dai, Y. and Ohtsuka, K. (2005): Enhanced expression of heat shock proteins in gradually dying cells and their release from necrotically dead cells. Exp. Cell Res., 310, 229-236.

Sumizawa, T. and Igisu, H. (2007): Apoptosis induced by acrylamide in SH-SY5Y cells. Arch. Toxicol., 81, 279-282.

Xanthoudakis, S. and Nicholson, D.W. (2000): Heat-shock proteins as death determinants. Nat. Cell Biol., 2, E163-165. 